This is the author's Post-print version (final draft post-refereeing as accepted for publication by the journal). The definitive, peer-reviewed and edited version of this article is published as: Permentier M., Bolt G. and van Ham M. (2011) Determinants of neighbourhood satisfaction and perception of neighbourhood reputation. Urban Studies 48(5), 977-996. http://dx.doi.org/10.1177/0042098010367860

\title{
Determinants of neighbourhood satisfaction and perception of neighbourhood reputation
}

\author{
Matthieu Permentier*, Gideon Bolt** \& Maarten van Ham*** \\ *\&**Utrecht University, Urban and Regional research centre Utrecht (URU), Utrecht \\ University, P.O. Box 80115, 3508 TC Utrecht, The Netherlands. Phone: +31-30-2531392, e- \\ mail: *m.permentier@geo.uu.nl,**g.bolt@geo.uu.nl \\ *** University of St Andrews, Centre for Housing Research (CHR), School of Geography \& \\ Geosciences, Irvine Building, North Street, St Andrews, Fife, KY16 9AL, UK. Phone \\ +44(0)1334 463912, Fax +44 (0)1334 463949, e-mail: ***maarten.vanham@st- \\ andrews.ac.uk
}

\begin{abstract}
It has been suggested that residential mobility behaviour and general well-being of residents of urban neighbourhoods are not only influenced by how residents themselves assess their neighbourhood, but also by how they think other city residents see their neighbourhood: the perceived reputation of the neighbourhood. There is a large body of literature on residents' satisfaction with their neighbourhood, but much less is known about how residents perceive the reputation of their own neighbourhood. Such knowledge might give important clues on how to improve the well-being of residents in deprived neighbourhoods by not only directly improving the factors that affect their own level of satisfaction, but also by improving the factors that residents think have a negative effect on the reputation of their neighbourhood. This paper examines whether there are differences in the determinants of neighbourhood satisfaction and the perceived reputation of the neighbourhood. Using data from a purpose designed survey to study neighbourhood reputations in the city of Utrecht, the Netherlands, we found that subjective assessment of the dwelling and neighbourhood attributes are more important in explaining neighbourhood satisfaction than in explaining perception of reputation. Objective neighbourhood variables are more important in explaining perception of reputation than in explaining neighbourhood satisfaction.
\end{abstract}

Keywords: neighbourhood satisfaction; neighbourhood reputation; neighbourhood characteristics, the Netherlands

\section{INTRODUCTION}

Increasing attention for urban neighbourhoods by policy makers caused a renewed interest in neighbourhood (dis)satisfaction (Parkes et al., 2002). The question of which neighbourhood attributes are most important in predicting satisfaction is of great interest to policy makers and potentially contributes to a better understanding of the success factors of neighbourhood regeneration. Neighbourhood satisfaction is known to be important in understanding residential mobility patterns and neighbourhood stability (Wolpert, 1966; Speare, 1974; Speare et al., 1975; Brown \& Moore, 1970). On the level of individual residents, those who are satisfied with their neighbourhood are thought not only to be less likely to move, but also to have a higher general quality of life (Mohan \& Twigg, 2007; Sirgy \& Cornwell, 2002).

Several authors have suggested that residential mobility behaviour and general wellbeing of residents are not only influenced by how residents assess themselves their 
neighbourhood, but also by how residents think others see their neighbourhood: the perceived reputation of the neighbourhood (Lee et al., 1994; Taylor, 1998; Wacquant, 1993). The (perceived) reputation of the neighbourhood affects people's wellbeing because the neighbourhood can be a source of social status that may provide a valuable psycho-social benefit to neighbourhood residents (Kearns et al., 2000; Wacquant, 2007). White (1987, p. 267) argues that the reputation of neighbourhoods is of increasing importance to residents: "Neighbourhood can be an important way of maintaining status in a mobile society. (...) Increasingly community itself, along with the neighbourhood, is something consciously purchased through a market, a bundle of goods that comes with residence".

There is a large body of literature on neighbourhood satisfaction. The literature distinguishes three main groups of determinants: personal/household characteristics; subjective evaluations of neighbourhood attributes and subjective evaluation of the dwelling; and objective neighbourhood characteristics. It has been found that subjective evaluations of neighbourhood attributes are much more important in explaining neighbourhood satisfaction than personal/household characteristics (Lu, 1999; Parkes et al., 2002) and objective neighbourhood attributes (Campbell et al., 1976; Carp, 1976; Galster, 1987).

Much less is known about how residents perceive the reputation of their own neighbourhood, or with other words, how they think other city residents see their neighbourhood (see also Permentier et al., 2007b). On the one hand it can be expected that neighbourhood satisfaction and the perception of neighbourhood reputation have overlapping determinants. On the other hand we know that even in neighbourhoods with a poor reputation residents can be satisfied with their neighbourhood (Amérigo \& Aragonés, 1990; St. John \& Clark, 1984; Lu, 1999). This upward bias in satisfaction can be partly attributed to selective mobility into and out of neighbourhoods and to the tendency of residents to think more positively about their residential environment when they lack the opportunity to move somewhere else (Brown \& Moore, 1970). These two mechanisms are less likely to have a large effect on peoples' perception of the reputation of their neighbourhood. A neighbourhood's reputation is a collective concept; a wide shared belief about the state of a neighbourhood. To some extent, residents internalise the collective view, as can be concluded from the strong correlation between residents' and non-residents' assessment of neighbourhood reputation (Curtis \& Jackson, 1977; Permentier et al., 2007b). Non-residents have no interest in downplaying the negative aspects of an area. Furthermore, they are less likely to have detailed knowledge of a neighbourhood and will tend to base their opinion on a limited set of objective neighbourhood characteristics rather than personal evaluations.

In this paper we will examine to which extent there are differences in the determinants of neighbourhood satisfaction and the perceived reputation of the neighbourhood. The aim is to come to a better understanding of the factors that are important in how people see their own neighbourhood and how they think others see their neighbourhood. Such understanding might give important clues on how to improve the wellbeing of residents in deprived neighbourhoods by not only directly improving their own level of satisfaction, but also by improving the factors that residents think have a negative effect on the reputation of their neighbourhood. We use data from a survey that was specifically designed to study neighbourhood reputations. The survey, including 1,102 residents in 24 different neighbourhoods, was carried out in the spring of 2006 in the city of Utrecht, The Netherlands.

\section{DETERMINANTS OF NEIGHBOURHOOD SATISFACTION AND PERCEPTION OF REPUTATION}

Neighbourhood satisfaction and the perception of neighbourhood reputation are related concepts. The former indicates how a resident assesses his or her neighbourhood, while the latter indicates how the resident thinks that other city residents assess their neighbourhood. Although the concepts of satisfaction and perception of reputation are related, we expect differences in the type of determinants that are significant and also in the size of the effects of 
these determinants. In the following section we discuss the determinants of neighbourhood satisfaction. Then, we will focus on the perception of reputation and its determinants.

\section{Determinants of neighbourhood satisfaction}

\section{Satisfaction with neighbourhood attributes and the dwelling}

Satisfaction with specific neighbourhood attributes is strongly correlated with overall neighbourhood satisfaction. Satisfaction with public services (Basolo \& Strong, 2002); satisfaction with schools (Parkes et al., 2002); satisfaction with the general appearance of neighbourhoods (Parkes et al., 2002); perceived safety (Basolo \& Strong, 2002; Harris, 2001; Mohan \& Twigg, 2007; Parkes et al., 2002); satisfaction with fellow-residents (Galster \& Hesser, 1981; Mohan \& Twigg, 2007) and nuisance of noise (Mohan \& Twigg, 2007) have all been found to be important predictors of satisfaction with the neighbourhood. Lu (1999) found a strong negative effect on neighbourhood satisfaction of a bother-index - an index that can either take a 1 (=residents stating that something in their neighbourhood is bothersome, e.g. noise, crime, traffic, and litter) or 0 (nothing bothersome). Several studies have shown that also satisfaction with the dwelling has a strong positive effect on satisfaction with the neighbourhood (Lu, 1999; Mohan \& Twigg, 2007).

Studies on neighbourhood satisfaction attach considerable importance to the perception of housing and neighbourhood conditions ( $\mathrm{Lu}, 1999)$. The general idea is that perception carries more weight in the explanation of neighbourhood satisfaction than objective neighbourhood characteristics (Galster \& Hasser, 1981; Parkes et al., 2002). Inclusion of perception of neighbourhood attributes in regression models not only reveals that perceptions are better predictors of satisfaction than objective variables, but also that some neighbourhood characteristics are not significant after controlling for residents' perceptions (St. John \& Clark, 1984; Parkes et al., 2002; Mohan \& Twigg, 2007). This implies that some objective characteristics only have an indirect effect on neighbourhood satisfaction, with perceptions of neighbourhood attributes as intermediary variables.

\section{Objective neighbourhood characteristics}

Although the effect of neighbourhood characteristics on neighbourhood satisfaction is partly mediated through perceptions of neighbourhood attributes, there is ample evidence of direct effects of objective neighbourhood conditions on neighbourhood satisfaction. It is found that those living in predominantly black or immigrant neighbourhoods are likely to be dissatisfied with their neighbourhood (Clark, 1992; Bobo \& Zubrinsky, 1996). Whether this is a result of racism or ethnic preferences (Bobo \& Zubrinsky, 1996), or whether this is the result of the association of black/ethnic neighbourhoods with crime, poverty and low-quality facilities (see Harris, 2001, on the racial proxy hypothesis) is unclear. Living in neighbourhoods with a high socioeconomic status is found to lead to a higher neighbourhood satisfaction than living in poverty areas (Stipak \& Hensler, 1983; Harris, 2001; Parkes et al., 2002; Mohan \& Twigg, 2007).

Studies have further found environmental cleanliness and quality of the housing stock in a neighbourhood to have a positive effect on neighbourhood satisfaction (Lee \& Guest, 1983; Jagun et al., 1990; St. John \& Bates, 1990; Basolo \& Strong, 2002) and high neighbourhood density to have a negative effect on satisfaction. Relative location of neighbourhoods is not often included in neighbourhood satisfaction studies, though proximity to shopping facilities can be generally expected to have a positive effect on neighbourhood satisfaction (Basolo \& Strong, 2002, p. 88).

\section{Personal and household characteristics}

Personal and household characteristics are thought to influence satisfaction mainly through selection effects. Younger people have been found to be less satisfied with their neighbourhood than elderly people (Lu, 1999; Parkes et al., 2002; Chapman \& Lombard, 2006), possibly because they had less time to select themselves into a pleasant environment. Also household composition is known to impact neighbourhood satisfaction. Galster \& 
Hesser (1981) found single women to be more dissatisfied with their neighbourhood than others. Parkes and colleagues (2002) found that the presence of children has a positive effect on neighbourhood satisfaction (see also Lu, 1999). It can be expected that households with children put more value on living in safe and spacious neighbourhoods and therefore select themselves into these particular types of neighbourhoods. Next to that, the presence of children has a positive impact on social interaction in the neighbourhood (Dekker \& Bolt, 2005), which on its turn leads to a higher neighbourhood satisfaction (Kasarda \& Janowitz, 1974; Speare et al., 1974; Parkes et al., 2002).

Socioeconomic status variables, like family income and educational level have been found to have a positive effect on satisfaction: a higher income and/or higher level of education lead to higher neighbourhood satisfaction (St. John \& Clark, 1984; Lu, 1999; Harris, 2001). Those with a high socio-economic status have more choice on the housing market and are therefore more likely to be able to select a dwelling in a neighbourhood of their preference. Homeowners are more satisfied with their neighbourhood than renters because they have in general more choice on the housing market (Lu, 1999; Harris, 2001; Parkes et al., 2002).

Evidence on the effect of ethnicity on neighbourhood satisfaction is mixed. Some studies show that ethnicity is a significant predictor of neighbourhood satisfaction (for example Campbell et al., 1976; Lu, 1999): whites are reported to be more satisfied with the neighbourhood than blacks. Other studies find however no ethnicity effect (Bolt, 2001; Parkes et al., 2002, Harris, 2001: St. John \& Clark, 1984).

\section{Determinants of perception of reputation}

\section{Satisfaction with neighbourhood attributes and the dwelling}

Evidence regarding the impact of satisfaction with neighbourhood attributes on perception of reputation is absent. We do believe however that the impact is likely to be smaller on perception of reputation than on neighbourhood satisfaction because the reputation of a neighbourhood is to a large extent created by other city residents, as is formulated by Suttles (1972, p. 13) "It is in their "foreign" relations that communities come into existence and have to settle on an identity and a set of boundaries which oversimplify their reality." It has indeed been found that the residents' perception of the neighbourhood reputation is to a large extent affected by the view of other city residents (Curtis \& Jackson, 1977; Permentier et al., 2007a). These other city residents are not likely to assess the reputation of a neighbourhood on the basis of detailed information of neighbourhood attributes, but will tend to base their view on a limited number of physical and - mainly - social characteristics of the neighbourhood (Permentier et al., 2007a; Suttles, 1972). The above leads to the first hypothesis: Assessment of different neighbourhood attributes is more important in explaining neighbourhood satisfaction than perception of reputation.

\section{Objective neighbourhood characteristics}

In their overview of neighbourhood characteristics that impact neighbourhood reputations Permentier et al. (2007a) state that objective social neighbourhood characteristics like ethnic composition and socioeconomic status are most important (see also Wacquant, 1993; Hortulanus, 1995; Garcia-Mira, 1997; Logan \& Collver, 1983), as these characteristics mirror those in the stratification process of society as a whole. It has also been shown that a high level of crime has a negative effect on reputations, although this effect is smaller than the effect of social composition (Sampson \& Raudenbusch, 2004). Furthermore, location of the neighbourhood (distance to city centre) is also thought to be important. Hastings \& Dean (2003) argue that neighbourhoods located at the fringe of the city are less well-known by nonresidents than neighbourhoods closer to the city centre, which has a negative impact on the reputation of neighbourhoods.

It can be argued that objective neighbourhood characteristics are more important for the explanation of perceived neighbourhood reputation than for the explanation of neighbourhood satisfaction. First, regarding neighbourhood satisfaction, the effect of 
objective neighbourhood characteristics may be weakened due to selection effects (Van Ham $\&$ Feijten, 2007). People select themselves into different types of neighbourhoods on the basis of their preferences. People who prefer to live in high density inner city neighbourhoods are likely to satisfied with their residential environment, but at the same time, they might be well aware that such neighbourhoods might have a poorer reputation than, for example, low density garden city neighbourhoods. Of course, peoples' perception of reputation may also be affected by selection effects as residents will tend to select themselves into a neighbourhood that meets their status aspirations. However, while some residents may derive status from where they live, others can be rather indifferent about it (De Wijs-Mulkens, 1999; Kearns et al., 2000). In contrast, being satisfied with the residential environment and increasing the level of satisfaction through residential mobility seem to be universal aims (Wolpert, 1966; Brown \& Moore, 1970).

Second, cognitive dissonance reduction (Festinger, 1957) may explain why objective neighbourhoods characteristics are more important in understanding reputations than neighbourhood satisfaction. Residents may upwardly adjust their assessment of their neighbourhood in case this neighbourhood does not fulfil the resident's needs and residents have no options to go to alternative neighbourhoods (Brown \& Moore, 1970). This partly explains why even in deprived neighbourhoods, the larger part of the residents tend to be satisfied. (Amérigo \& Aragonés, 1990; St. John \& Clark, 1984; Lu, 1999: Parkes et al., 2002; Mohan \& Twiggs, 2007)). It is likely that the process of cognitive dissonance reduction is less relevant for the explanation of perception of reputation. The perception of reputation is to a large extent influenced by how other city residents assess the reputation of the neighbourhood and these non-residents do not have the need to upwardly adjust their ideas, simply because they themselves do not live in the neighbourhood. The above leads to the formulation of the second hypothesis: Objective neighbourhood variables are more important in explaining perception of neighbourhood reputation than neighbourhood satisfaction.

\section{Personal- and household variables}

Kearns and colleagues (2000) found that men are more concerned to derive status from their home than women and age, income, job status and owner occupation were found to have a positive effect on the status that residents attribute to their home. It may be expected that these variables also relate to the importance attached to the reputation of the neighbourhood. Income is among the most important determinants of neighbourhood choice (Clark et al., 2006). The neighbourhood functions more as status symbol for higher income groups, as household with a lower income are more concerned with finding a neighbourhood which suits their basic needs (Anderiesen \& Reijndorp, 1989). The difference in aspirations can be explained by the level of choice people have on the housing market. If people's choices are restricted due to a lack of resources, it is not very likely that the reputation of the neighbourhood is the first priority when choosing a neighbourhood. They will put more value on for example the safety of the neighbourhood (Driessen \& Beerenboom, 1983). On the other hand, people with a lot of choice (highly educated, high income, home-owner) can be expected to select a neighbourhood because of a good reputation and are therefore more positive regarding perception of reputation (De Wijs-Mulkens, 1999).

An interesting question is whether the relative weight of the individual socioeconomic characteristics will be the same in a model explaining perception of reputation as compared to a model of neighbourhood satisfaction. The finding that people adjust their (neighbourhood) aspirations to their prospect of improvement (Festinger, 1957; Lu, 1999: Parkes et al., 2002) implies that socioeconomic status has a smaller effect on satisfaction than on perception of reputation. As we argued before, cognitive dissonance reduction can be expected to play a smaller role when perception of reputation is concerned. This expectation is further underpinned by that fact that low-income and high-income groups tend to share the same perception with regard to the reputation hierarchy of urban neighbourhoods (Logan \& Collver, 1983: Permentier et al., 2007a). Since low-income groups are overrepresented in neighbourhoods with a bad reputation, they will have on average a more negative perception 
of the neighbourhood than high-income groups (when objective neighbourhood characteristics are not controlled for).

Regarding ethnicity it can be argued that non-western immigrants may be more dissatisfied with the neighbourhood because they tend to live in, on average, neighbourhoods of lower quality than the native majority. At the same time, it may be expected that the perception of their neighbourhood's reputation is more positive, once objective neighbourhood conditions are controlled for, as the point of reference may be different for them compared to native Dutch (Dekker \& Bolt, 2005; Permentier et al., 2006). This is because the networks of members of minority ethnic groups are to a large extent restricted to the own ethnic group (Dagevos, 2005), which implies that many of their friends and family members live in (similar) low-quality neighbourhoods. That means that a member of a minority ethnic groups who lives in an 'average' neighbourhood in terms of prosperity, may derive more status from that within his own community than a native Dutch resident living in the same neighbourhood. The above leads to the formulation of the third hypothesis: Socioeconomic status and ethnicity are more important in explaining perception of reputation than neighbourhood satisfaction.

\section{RESEARCH AREA AND DATA}

Due to a lack of information on neighbourhood reputations in existing published secondary data in the Netherlands, we collected our own data. In the spring of 2006 we conducted a survey amongst residents in the city of Utrecht. The survey was explicitly focussed on measuring reputations of the own neighbourhood and other neighbourhoods within Utrecht. With 281,011 residents (GBA City of Utrecht, 2006) Utrecht is the fourth largest city in the Netherlands and is centrally located. Compared with the two largest cities in the Netherlands (Amsterdam and Rotterdam), the relatively large proportion of medium and highly-educated residents in Utrecht is striking (in 2004: 69.4 percent, Rotterdam: 47 percent; and Amsterdam, 56.4 percent). Utrecht has a large university and Utrecht graduates find the city centre and surrounding neighbourhoods to be attractive residential environments. Partly as a result of the university connection, the city has a high percentage of residents under the age of 25. Compared with the other three cities, Utrecht has a low percentage of non-western immigrants (23.8 percent in 2006 compared with 34.3 percent in Amsterdam, 35.4 percent in Rotterdam, and 32.2 percent in The Hague; GBA City of Utrecht 2006; O+S Amsterdam, 2006). The segregation index of non-western immigrants is similar to that of the three other cities (Utrecht, 37.4; Amsterdam, 36.3; Rotterdam, 38.5; The Hague, 46.1; Bolt et al., 2006).

[Figure 1 around here]

Measuring neighbourhood reputations required the identification of (administrative) neighbourhoods that had a wide recognition among respondents. Using a small telephone survey, we probed different neighbourhood names on city-residents to find out which neighbourhoods were known well enough to be included in our questionnaire. On the basis of this survey we selected 24 which varied on such aspects as housing density, housing stock, socioeconomic composition and ethnic composition (see Figure 1).

The selected neighbourhoods differ on socio-demographic, socio-cultural and socioeconomic grounds from each other. For example, some neighbourhoods contain many households with a relatively low income and with a relative high unemployment rate: Overvecht, Kanaleneiland, Ondiep, Sterrenwijk, and Zuilen all have an average household income below $€ 13,000$ per year and an unemployment rate of over eight per cent. Other neighbourhoods are relatively affluent: Tuindorp, Wilhelminapark, and Wittevrouwen all have an average household income above $€ 18,000$ per year and an unemployment rate under four per cent. Some of the socio-economic disadvantaged areas have a strong overrepresentation of ethnic minorities (over 40 per cent in Kanaleneiland and Overvecht), while other poor areas contain mostly native Dutch people employed in blue-collar jobs (for 
example, Sterrenwijk has only 12,0 per cent ethnic minorities). The building period of the 24 neighbourhoods is rather diverse. The city centre contains buildings from all periods, starting in the Middle ages. The neighbourhoods directly surrounding the old city centre have been built in the nineteenth century. Most of these neighbourhoods used to be rather unpopular, but have gentrified over the last 20 years. In the north of the city (Overvecht) and the south-west (Kanaleneiland), large-scale post-war housing estates can be found. Voordorp, Rijnsweerd and Lunetten are 1970-1990 neighbourhoods with a suburban feel. The area of Leidsche Rijn has been developed in the 1990s, though large scale construction is still taking place here.

Within the selected neighbourhoods we randomly selected addresses of respondents. We oversampled one neighbourhood and used a random selection of this oversample population in this paper. This resulted in a total of 1,102 cases. Comparison of our sample with the population of Utrecht shows that in our sample Turks and Moroccans, persons between 18-44 years old and single people are slightly underrepresented, while owneroccupants are overrepresented.

\section{METHOD OF DATA ANALYSIS}

The two dependent variables have been made operational by asking people to grade their satisfaction with their neighbourhood and their perception of the neighbourhood reputation. The following two questions were asked: "Please indicate what grade between 1-10 you would give to your neighbourhood" with 1 is very dissatisfied and 10 is very satisfied; and "Please indicate on a 1-5 point scale, how do you think other Utrecht-residents assess the reputation of your neighbourhood", with 1 is very negative and 5 is very positive. Since the dependent variables neighbourhood satisfaction and perception of reputation can be considered ratio variables, we used linear regression models. ${ }^{1}$ A summary overview of all variables can be found in Table 1 . The choice variables have been measured by asking respondents to what extend they experienced freedom in the choice of respectively their dwelling and their neighbourhood. Subjective assessments of neighbourhood attributes is measured by taking the average score on a five-point scale of eight different neighbourhood attributes (satisfaction with location, appearance, accessibility, green space, shopping facilities, safety, contact with fellow-residents, population composition).

[Table 1 around here]

To take into account that in our data individuals are clustered in neighbourhoods, we use multilevel models. A basic two-level model consists of a single outcome variable at the lowest level, while having explanatory variables at the individual level (level 1) and the neighbourhood level (level 2). We use a random intercept model in which the regression intercept varies across neighbourhoods, but the regression slopes are fixed. Thus the intercept varies randomly across individuals and neighbourhoods, but the relationship between the dependent and the independent variables is assumed to be the same for all individuals within a neighbourhood (Snijders \& Bosker, 1999). Model estimation was carried out using the software package STATA 10.

\footnotetext{
1 Strictly speaking, the 1-5 and 1-10 scales should be modelled with and ordered logit function. However we choose a linear function because this type of modelling provides -in contrast to ordered logit- variances on both the individual level and neighbourhood level. A comparison of the direction and significance of variables of the ordered logit model and linear model revealed almost identical results. The ordered logit models are available on request from the authors.
} 


\section{RESULTS}

Neighbourhoods on the east side of Utrecht (such as Wilhelminapark, Wittevrouwen, Rijnsweerd) are given the highest satisfaction and perceived reputation ratings, while neighbourhoods in the north (Ondiep, Overvecht, Zuilen) and southwest (Kanaleneiland) are given the lowest ratings. The correlation between neighbourhood satisfaction and perception of reputation is relatively modest at 0.584 , which illustrates that the concepts are related, but also measure different things. Table $2 \mathrm{a}$ and $2 \mathrm{~b}$ show the results of a series of linear regression models of neighbourhood satisfaction (model 1-5) and perception of reputation of residents (model I-V). Model 1 and model I are intercept-only models which contain no explanatory variables. In model 2 and II personal and household variables are added. In model 3 and III the degree of dwelling- and neighbourhood choice are included. This allows to control the impact of individual and household characteristics for selection effects. Model 4 and IV add a composite index of satisfaction with different neighbourhood attributes, dwelling satisfaction and contacts in the neighbourhood. Inclusion of these variables allows us to study the effect of satisfaction variables on both dependent variables. In model 5 and $\mathrm{V}$ objectively measured neighbourhood characteristics are introduced. For every model the deviance and the variation on individual- and neighbourhood level are given.

[Table 2a around here]

[Table $2 \mathrm{~b}$ around here]

The intercept-only models (model 1 and I) function as a benchmark for the other models and allow us to decompose the total variance into an individual level-component (level 1) and a neighbourhood level-component (level 2) (Snijders \& Bosker, 1999; Hox, 2002). The intra-class correlation coefficient (ICC) can be summarized as the proportion of variance accounted for on the neighbourhood level and indicates to what extent variation of the dependent variable is caused by the grouping structure in the sample (Snijders \& Bosker, 1999). The ICC of model 1 is calculated by dividing the unexplained variance on level 2 $(0.587)$ by the total unexplained variance $(1.374+0.587)$. The ICC for model 1 shows thus that 29.9 percent of the variation in neighbourhood satisfaction between respondents can be attributed to the grouping structure in the sample. The ICC for model I shows that 49.5 percent of the variation in perception of reputation can be attributed to the grouping structure in the sample. Thus in both models, neighbourhood characteristics can potentially play an important role in explaining the outcome variable. But the potential of neighbourhood characteristics is likely to be greater in explaining variation in perception of reputation and variables on the individual level are likely to be more important in explaining variation in satisfaction scores. This seems to be a preliminary confirmation of the hypothesis that (objective) neighbourhood variables are relatively more important in the explanation of perception of reputation (hypothesis 2), while assessment of neighbourhood attributes (on the individual level) are more important for the explanation of neighbourhood satisfaction (hypothesis 1).

\section{[Table 3 around here]}

In model 2 and II a block of personal- and household variables are added. Table 3 gives a summary of the explained variance on each level for all subsequent models. Differences between neighbourhoods regarding satisfaction are for $9.9 \%$ explained by the population composition, while in the perception of reputation model population composition does hardly explain any differences between neighbourhoods $(0.1 \%)$. On the individual level, the block of personal- and household variables explain $4.6 \%$ of the variation of the satisfaction model and $0.5 \%$ of variation in the perception of reputation model.

In both models, gender has a positive effect, though it is only significant in the satisfaction model. The results indicate that women are generally more satisfied with their neighbourhood. The effect of age is positive and significant in both models, having a higher 
significance level for neighbourhood satisfaction than for perception of reputation. Older residents are more satisfied with the neighbourhood and also perceive the neighbourhood's reputation more positive than younger residents. Presence of children is a significant predictor of neighbourhood satisfaction, but not for perception of reputation. Regarding the socioeconomic variables, only tenure status is a significant predictor of neighbourhood satisfaction and perception of reputation: home-owners are more satisfied with their neighbourhood and perceive the reputation of their neighbourhood higher than renters. The effects of income, level of education and employment status are all insignificant in the two models. This is likely to be caused by the fact that tenure captures the effect of these socioeconomic variables. Ethnicity has no effect on neighbourhood satisfaction but is a significant predictor of perception of reputation: an individual belonging to a non-western minority group perceives the reputation of the own neighbourhood significantly higher than native Dutch and western-minority groups.

In model 3 and III indicators of the degree of choice with regard to the selection of the dwelling and the neighbourhood are included in the model. The explained variance of model 3 is $.21 .0 \%$ and $6.0 \%$ (compared to the intercept-only model) on the neighbourhood level in respectively the satisfaction and perception of reputation model. Regarding the individual level, this model explains $11.2 \%$ on individual level in the satisfaction model and $4.9 \%$ in the perception of reputation model. These figures indicate that the variables explain more of the variance of the satisfaction model than the perception of reputation model.

People who experienced freedom in the choice of either their dwelling or their neighbourhood are much more likely to be satisfied with their neighbourhood and perceive the reputation of their neighbourhood to be higher than people who did not experience this freedom. The results of model 3 and model III indicate that the effect of personal and household characteristics can to a certain extent be explained by selection effects. Inclusion of choice variables causes age and presence of children to be no longer significant in the models. Older people have selected themselves into nicer neighbourhoods because they generally had a large degree of choice. The same mechanism seems at work for households with children. However, gender in the satisfaction model is still significant, while tenure is significant in both models. Ethnicity continues to be a significant variable in the perception of reputation model.

Model 4 and IV introduce, besides social contacts within the neighbourhood, two type of satisfaction variables: satisfaction with the dwelling and five statements related to satisfaction with different neighbourhood attributes (population composition, contact with neighbours, social safety, shops and green spaces) Neighbourhood level variance decreases in both models, although the decrease in variance is clearly larger for neighbourhood satisfaction than for perception of reputation. The percentage explained variance on the neighbourhood level (compared to the intercept-only model) is $66.1 \%$ for satisfaction and only $27.8 \%$ for perception of reputation, indicating that this model with dwelling satisfaction and assessment of different neighbourhood attributes have a much larger impact on neighbourhood satisfaction than on the perception of neighbourhood reputation. On the individual level, the variables lead to a total of $43.1 \%$ explained variance in the satisfaction model and to $21.1 \%$ explained variance in the perception of reputation model. These results support hypothesis 1: the assessment of different types of neighbourhood attributes is more important in explaining neighbourhood satisfaction than perception of reputation.

Dwelling satisfaction is a significant predictor of neighbourhood satisfaction: residents who are satisfied with their dwelling are much more likely to be satisfied with the neighbourhood than residents who are unhappy with their current dwelling (see also Lu, 1999; Mohan \& Twigg, 2007). Positive assessment of the five neighbourhood attributes has a positive effect on satisfaction with the neighbourhood, which is in line with previous research (Lu, 1999). Residents who are satisfied with facilities such as shops and green spaces are more satisfied with the neighbourhood in general. The social aspect of the neighbourhood is also important: satisfaction with the neighbourhood composition, contact with fellow residents and social safety appear to be equally important in this matter. Interestingly, actual social contacts within the neighbourhoods are not significant in this model. 
In the perception of reputation model only three of five neighbourhood attributes are significant, whereas satisfaction with the dwelling does not have an effect on the perceived reputation. This is in line with what we expected, since it is unlikely that dwelling satisfaction plays a role in how people think that other city residents see their neighbourhood. The presence of family in the neighbourhood has a significant positive effect on perceived reputation. Controlling for dwelling satisfaction and evaluation of neighbourhood attributes and social contacts leads to the disappearance of the effect of dwelling choice in the neighbourhood satisfaction model. Apparently this variables has only an indirect impact on satisfaction which is through satisfaction with neighbourhood attributes and dwelling satisfaction. In contrast, in the perception of reputation model only the significance of tenure and ethnicity is channelled through satisfaction with attributes, while the effect of choice of neighbourhood is still significant (although the effects are smaller).

In model 5 and $\mathrm{V}$ different objective neighbourhood characteristics are introduced. Inclusion of these variables has a negligible effect on the regression parameters of the individual variables, though tenure becomes just significant on the $\mathrm{p}=0.1$ level. Ethnicity and tenure shows up as the only two individual variables that have an impact on perception of reputation, while gender and presence of children in the household have an effect on neighbourhood satisfaction. Therefore, it can be concluded that hypothesis 3 is confirmed.

Both model 5 and $\mathrm{V}$ show a decrease of the explained variance at the level of the neighbourhood to almost zero. The models explain, compared to the intercept-only model, $93.3 \%$ of the variance on the neighbourhood level in the satisfaction model and $91.1 \%$ in the perception of reputation model. ${ }^{2}$ Thus, the addition of objective neighbourhood variables leads to a substantively higher explained variance than the previous model, but the increase in explained neighbourhood variance is much larger for the perception of reputation model than for the satisfaction model. Therefore hypothesis 2 which stated that objective neighbourhood variables are more important in explaining perception of neighbourhood reputation than neighbourhood satisfaction is confirmed.

In both models, a high average household income in the neighbourhood is associated with a high satisfaction and high perceived reputation. Crime and distance to the city centre have no significant effect in the satisfaction model, but both have a negative effect in the perception of reputation model. In earlier research, Sampson and Raudenbusch (2004) found the level of crime to be correlated with perceived levels of disorder which in its turn impacts the stigmatization of neighbourhoods. The coefficients of percentage non-western immigrants reveal that both for neighbourhood satisfaction and perception of reputation a higher share of non-western immigrants lead to respectively lower neighbourhood satisfaction and to lower perception of the neighbourhood's reputation. Thus even after controlling for the economic status of the neighbourhood, ethnic composition of the population continued to be highly significant. The number of government facilities, such as schools and health care facilities, has a positive effect on neighbourhood satisfaction: residents living in neighbourhoods with a large number of such facilities are more satisfied with the neighbourhood. A similar effect on perception of reputation is however absent. The above results show that there are more objective neighbourhood variables significant in the perception of reputation model than in the satisfaction model. At the same time it becomes clear that for neighbourhood satisfaction assessments of neighbourhood attributes are more important than objective neighbourhood variables. For perception of reputation it is the opposite: objective variables are more important in explaining the perception of reputation than subjective variables.

\footnotetext{
${ }^{2}$ Explained variance on individual level (1-level) is not given, since 2-level variables cannot explain variance on the first level (see Hox, 2002)
} 


\section{DISCUSSION}

In this paper we have argued that it is not only important to understand how residents themselves assess their neighbourhood, but also how they think that other city residents assess their neighbourhood. We have suggested that neighbourhood satisfaction and perceived reputation are related concepts and that these may overlap to a certain extent, but that at the same time the (type of) determinants of these concepts might have a different nature. We found that subjective assessments of neighbourhood attributes are more important in explaining neighbourhood satisfaction than perceived reputation. At the same time, objective neighbourhood characteristics contribute more in explaining perceived reputation than neighbourhood satisfaction. As expected, the ethnic composition of neighbourhoods as well as average neighbourhood income are the strongest determinants of perceived reputation, which reflects the stratification process of society as a whole.

Personal- and household characteristics have no direct effect on either neighbourhood satisfaction or perceived reputation, with the exception of ethnicity in the perceived reputation model and gender and the presence of children in the satisfaction model. The other personal and household characteristics are channelled through selection mechanisms (degree of choice regarding dwelling and neighbourhood) and through satisfaction with neighbourhood attributes. Older residents are for example more satisfied with the neighbourhood and more positive about the reputation of the neighbourhood, but this effect disappears after controlling for the choice they had in selecting their residence or neighbourhood.

Housing choice turned out to have a positive effect on both neighbourhood satisfaction and perception of reputation. This effect is only indirect in both the case of neighbourhood satisfaction and perceived reputaiton. People who experience freedom in the choice of their dwelling and neighbourhood are likely to be satisfied with the dwelling and neighbourhood attributes, which on their turn have a positive impact on neighbourhood satisfaction. In contrast, the perceived neighbourhood choice has an independent positive effect on neighbourhood satisfaction and perception of reputation. This confirms the hypothesis of Kearns \& Parkinson (2001) that reputation problems especially arise when a neighbourhood is perceived to be a place where people become 'trapped'.

On the basis of these results we argue that models of residential satisfaction and residential mobility should include choice variables. Very often, significant effects of individual variables (like income, tenure and age) are explained in terms of housing choice, but housing choice itself is seldom included as explanatory variable in regression models. However more work needs to be done in terms of testing the validity and reliability of the perceived choice concept.

The results of our research potentially have implications for urban policy and especially policy aimed at the regeneration of deprived neighbourhoods. In the Netherlands context one of the goals of urban renewal is to improve the relative position of the neighbourhood within cities (Priemus \& Van Kempen, 1999). In improving neighbourhoods, policymakers have given much attention to measures to improve the satisfaction levels of current neighbourhood residents. However, satisfaction levels may present a too rosy picture of the neighbourhood, due to processes of cognitive dissonance reduction: residents in deprived areas tend to upwardly adjust their level of satisfaction because of a lack of choice. Successful regeneration is not just about the current residents, but also about making neighbourhoods attractive for other city residents.

The results of this research show that our perceived reputation concept might be a valuable alternative measure of the relative attractiveness of neighbourhoods in a city. Perceived reputation is less subject to cognitive dissonance reduction and more linked to objective characteristics of the neighbourhood than neighbourhood satisfaction. Policy makers concerned with urban renewal could learn from our research in terms of the expected outcomes of policy measures. Policy measures aimed to improve satisfaction with neighbourhood attributes and to create a more mixed social composition of the neighbourhood will promote both neighbourhood satisfaction and perceived reputation. However, improving the quality of dwellings is likely only to have an effect on 
neighbourhood satisfaction as dwelling satisfaction has a positive effect on satisfaction with the neighbourhood, but not on perceived reputation. In addition, perceived reputation is thought to be likely to influence behaviour of residents (Permentier et al., 2007). Policy measures to improve the perceived reputations of neighbourhoods might improve neighbourhoods through selective residential mobility and more participation of residents in their neighbourhood.

\section{Acknowledgements}

Matthieu Permentier is grateful to the School of Geography \& Geosciences, University of St Andrews for their kind invitation and support for a short research stay in 2007.

\section{References}

Amérigo, M. and Aragonés, J.I. (1990) Residential satisfaction in council housing, Journal of Environmental Psychology, 74, pp. 515-526.

Anderiesen, G. and Reijndorp, A. (1989) Gescheiden werelden: sociale segmentering in 19e eeuwse stadsvernieuwingswijken. Amsterdam: CGO-UvA.

Basolo, V. and Strong, D. (2002) Understanding the neighborhood: From residents' perceptions and needs to action, Housing Policy Debate, 13, pp. 83-105.

Bobo, L. and Zubrinsky, C. L. (1996) Attitudes on residential integration: Perceived status differences, mere in-group preference, or racial prejudice? Social Forces, 74, pp. 883909.

Bolt, G. (2001) Wooncarrières van Turken en Marokkanen in ruimtelijk perspectief. Utrecht: Faculteit Ruimtelijke Wetenschappen.

Bolt, G., Van Ham, M. and Van Kempen, R. (2006) Allochtonen op de Woningmarkt. Ruimtelijke Segregatie en Verhuisdynamiek, in: F. Van Tubergen and I. Maas (eds.) Allochtonen in Nederland in international perspectief, pp. 189-216. Amsterdam: Amsterdam University Press.

Brown, L. A. and Moore, E.G. (1970) The intra-urban migration process: a perspective, Geografiska Annaler, 52, pp. 1-13.

Campbell, A., Converse, P.E. and Rodgers, W.L. (1976) The Quality of American Life: Perceptions, Evaluations and Satisfactions. New York: Russell Sage.

Carp, F., Zawadski, R. and Shokron, H. (1976) Dimensions of urban environmental quality, Environment and Behavior, 8, pp. 239-265.

Chapman, D. W. and Lombard, J.R. (2006) Determinants of neighborhood satisfaction in feebased gated and nongated communities, Urban Affairs Review, 41, pp. 769-799.

Clark, W. A. V., Deurloo, M. C. and Dieleman, F. (2006) Residential mobility and neighbourhood outcomes, Housing Studies, 21, pp. 323-342.

Clark, W. A. V. (1992) Residential preferences and residential choices in a multiethnic context, Demography, 29, pp. 451-466.

Curtis, R.F. and Jackson, A.F. (1977) Inequality in American communities. New York: Academic Press.

Dagevos, J. (2005) Gescheiden werelden? De etnische signatuur van vrijetijdscontacten van minderheden, Sociologie, 1, pp. 52-69.

Dekker, K. and Bolt, G. (2005) Social cohesion in post war estates in the Netherlands: differences between social-economic and ethnic groups, Urban Studies, 42, pp. $2447-$ 2470.

De Wijs-Mulkens, E. (1999) Wonen op stand - lifestyles en landschappen van de culturele en economische elite. Amsterdam: Het Spinhuis.

Driessen, F. M. H. M. and Beereboom, H.J.A. (1983) De kwaliteit van het stedelijk leefmilieu: Bewoners en hun voorkeuren. Den Haag/Utrecht: RPD/DGVH/Vakgroep Theorie \& Methodologie van de Sociologie.

Festinger, L. (1957) A Theory of Cognitive Dissonance. Stanford: Stanford University Press. 
Galster, G. (1987) Homeowners and Neighborhood Reinvestment. Durham, London: Duke University Press.

Galster, G. and Hesser, G.W. (1981) Residential Satisfaction. Compositional and Contextual Correlates, Environment \& Behavior, 13, pp. 735-758.

Garcia-Mira, R., Arce, C. and Sabucedo, J.S. (1997) Perceived quality of neighbourhoods in a city in northwest Spain: an individual differences scaling approach, Journal of Environmental Psychology, 17, pp. 243-252.

GBA City of Utrecht (2006), Buurtmonitor (http://utrecht.buurtmonitor.nl/; accessed 20 february 2006)

Goldstein, H. (1995) Multilevel Statistical Models. London: Edward Arnold.

Harris, D. (2001) Why are whites and blacks averse to black neighbors? Social Science Research, pp. 100-116.

Hastings, A. and Dean, J. (2003) Challenging images: tackling stigma through estate regeneration, Policy \& Politics, 31, pp. 171-184.

Hortulanus, R. P. (1995) Stadsbuurten - bewoners en beheerders in buurten met uiteenlopende reputaties. Den Haag: VUGA.

Hox, J. (2002) Multilevel Analysis. Techniques and Applications. Mahwah, NJ: Lawrence Erlbaum Associates.

Jagun, A., Brown, D.R., Milburn, N.G. and Garry, L.E. (1990) Residential satisfaction and socioeconomic and housing characteristics of urban black adults, Journal of Black Studies, 21, pp. 40-51.

Kasarda, J.D. and Janowitz, M. (1974), Community attachment in mass society, American Sociological Review, 39, pp. 328-339.

Kearns, A., Hiscock, R., Ellaway, A. and Macintyre, S. (2000) 'Beyond Four Walls'. The Psycho-social Benefits of Home: Evidence from West Central Scotland, Housing Studies, 15, pp. 387-410.

Kearns, A. and Parkinson, M. (2001). The significance of neighbourhood, Urban Studies, 12, pp. 2103-2110.

Lee, B.A. \& Guest, A.M. (1983) Determinants of neighborhood satisfaction: A metropolitanlevel analysis, The Sociological Quarterly, 24, pp. 287-303.

Lee, B. A., Oropesa, R.S. and Kanan, J.W. (1994) Neighborhood context and residential mobility, Demography, 31, pp. 249-270.

Logan, J. R. and Collver, O.A. (1983) Residents' perceptions of suburban community differences, American Sociological Review, 48, pp. 428-433.

Lu, M. (1999) Do people move when they say they will? Inconsistencies in individual migration behavior, Population and Environment, 20, pp. 467-488.

Mohan, J. \& Twigg, L. (2007) Sense of place, quality of life and local socioeconomic context: Evidence from the survey of English housing, 2002/03, Urban Studies, 44, pp. 20292045

O+S Amsterdam (2006) Amsterdam in Cijfers (http://www.os.amsterdam.nl/feitenencijfers/amsterdamincijfers2006; accessed on 30 March 2006)

Parkes, A., Kearns, A. and Atkinson, R. (2002) What makes people dissatisfied with their neighbourhoods? Urban Studies, 39, pp. 2413-243.

Permentier, M. \& Bolt, G. (2006) Woonwensen van allochtonen. Utrecht: DGW/NETHUR.

Permentier, M., Bolt, G. and Van Ham, M (2007a). Neighbourhood reputations: differences and similarities between internal and external reputations. AAG-Conference, San Francisco.

Permentier, M., Van Ham, M. and Bolt, G. (2007b) Behavioural responses to neighbourhood reputations, Journal of Housing and the Built Environment, 22, pp. 199-213.Priemus, H. and Van Kempen, R. (1999) Restructuring urban neighbourhoods in the Netherlands: four birds with one stone, Netherlands Journal of Housing and the Built Environment, 14, pp. 403-411. 
Sampson, R. J. and Raudenbush, S.W. (2004) Seeing disorder: neighborhood stigma and the social construction of broken windows, Social Psychology Quarterly, 67, pp. 319342.

Sirgy, M. J. and Cornwell, T. (2002) How neighborhood features affect quality of life, Social Indicators Research, 59, pp. 79-114.

Snijders, T. and. Bosker, R. (1999) Multilevel Analysis. An introduction to basic and advanced multilevel modeling. London, Thousand Oakes, New Delhi: SAGE Publications.

Speare, A. (1974) Residential satisfaction as an intervening variable in residential mobility, Demography, 11, pp. 173-188.

Speare, A., Goldstein, S. and Frey, W.F. (1975) Residential mobility, migration, and metropolitan change. Cambridge, MA: Ballinger.

Stipak, B. and Hensler, C. (1983) Effect of neighborhood racial and socioeconomic composition on urban residents' evaluations of their neighbourhoods, Social Indicators Research, 12, pp. 311-320.

St. John, C. and Bates, N.A. (1990) Racial composition and neighborhood evaluation, Social Science Research, 19, pp. 47-61.

St. John, C. and Clark, F. (1984) Racial differences in dimensions of neighborhood satisfaction, Social Indicators Research, 15, pp. 43-60.

Suttles, G. D. (1972) The social construction of communities. Chicago and London: The University of Chicago Press.

Taylor, M. (1998) Combating the social exclusion of housing estates, Housing Studies, 13, pp. 819-832.

Van Ham, M. and Feijten, P. (2008) Who wants to leave the neighbourhood? The effect of being different from the neighbourhood population on wishes to move, Environment and Planning A, 40, pp. 1151-1170.

Wacquant, L. J. D. (1993) Urban outcasts: stigma and division in the black American ghetto and the French periphery, International Journal of Urban and Regional Research, 19, pp. 366-383.

Wacquant, L. (2007). Territorial stigmatization in the age of advanced marginality, Thesis Eleven, 91, pp. 66-77.

White, M. (1987) American Neighbourhoods and Residential Differentiation. New York: Sage Foundation.

Wolpert, J. (1966) Migration as an adjustment to environmental stress, Journal of Social Issues, pp. 92-102. 


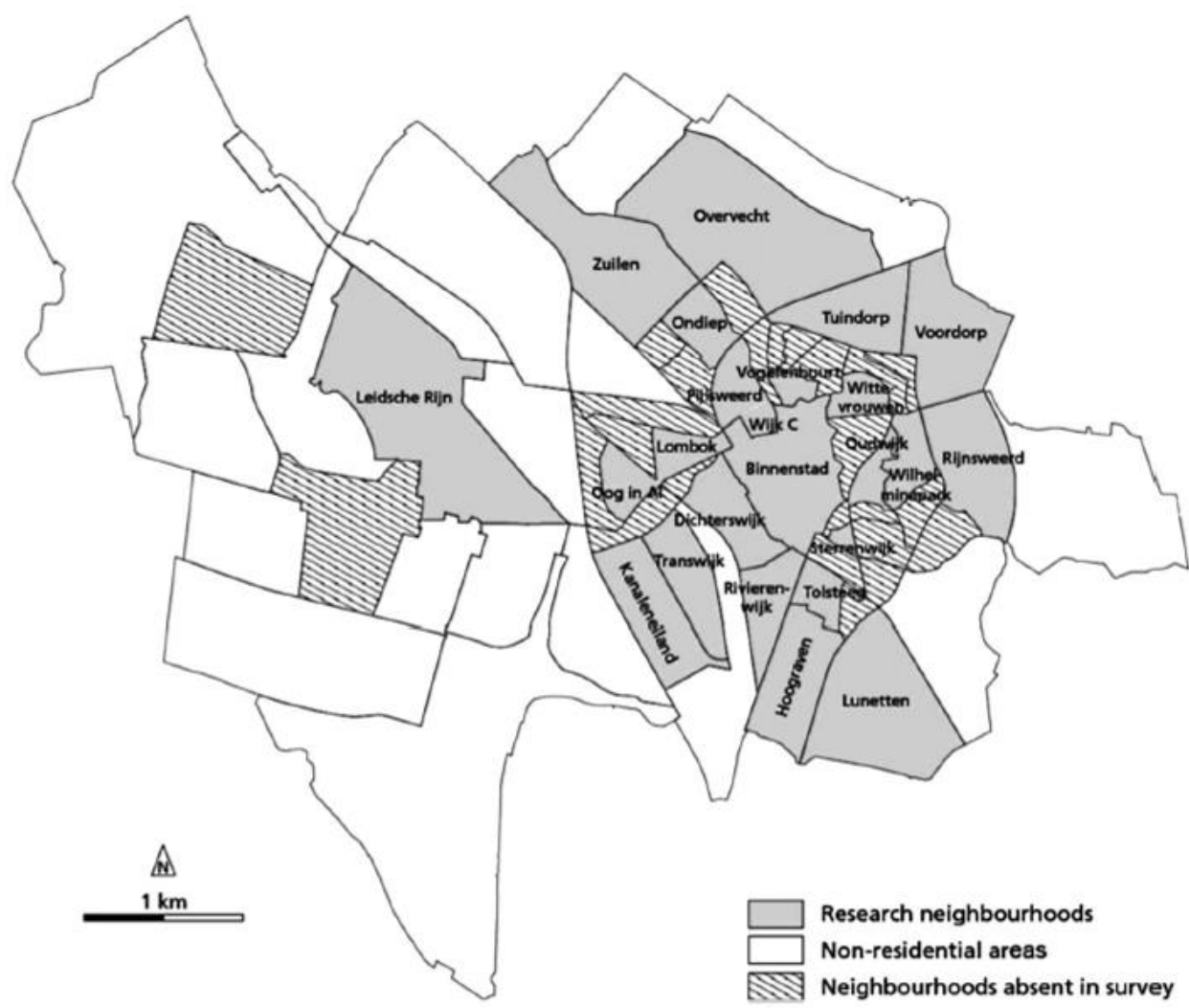

Figure 1. Research neighbourhoods in the city of Utrecht. 
Table 1. Descriptive statistics for the variables used in the analyses $(N=1095)$

\begin{tabular}{|c|c|c|c|}
\hline & $N($ percentage $)$ & Mean (S.D.) & Minimum-Maximum \\
\hline \multicolumn{4}{|l|}{ Individual-level variables } \\
\hline Neighbourhood satisfaction (dependent) & & $7.32(1.4)$ & $1-10$ \\
\hline Perception of reputation (dependent) & & $3.46(1.0)$ & $1-5$ \\
\hline \multicolumn{4}{|l|}{ Gender } \\
\hline Female & $601(54.9)$ & & \\
\hline Male & $494(45.1)$ & & \\
\hline Age & & $44.4(15.0)$ & 19-94 \\
\hline \multicolumn{4}{|l|}{ Children in household } \\
\hline Yes & $377(34.4)$ & & \\
\hline No & $718(65.6)$ & & \\
\hline \multicolumn{4}{|l|}{ Ethnicity" } \\
\hline Belonging to ethnic minority & $103(9.4)$ & & \\
\hline Not belonging to ethnic minority & $992(91.6)$ & & \\
\hline \multicolumn{4}{|l|}{ Level of education ${ }^{\mathrm{b}}$} \\
\hline Low & $208(19.0)$ & & \\
\hline Middle & $271(24.7)$ & & \\
\hline High & $616(56.3)$ & & \\
\hline \multicolumn{4}{|l|}{ Employment status } \\
\hline Employed & $757(69.1)$ & & \\
\hline Unemployed & $338(30.9)$ & & \\
\hline Net monthly household income $(x 100 €)$ & & $21.4(10.0)$ & $6.8-38$ \\
\hline \multicolumn{4}{|l|}{ Tenure status } \\
\hline Owner-occupant & $669(61.1)$ & & \\
\hline Renter & $426(38.9)$ & & \\
\hline Current dwelling first choice $($ ref. $=$ not $)$ & $827(75.5)$ & & \\
\hline \multicolumn{4}{|l|}{$($ ref. $=$ not $)$} \\
\hline Dwelling satisfaction & & $7.7(1.5)$ & $1-10$ \\
\hline \multicolumn{4}{|c|}{ Satisfaction with the following neighbourhood attributes } \\
\hline Neighbourhood population & & $3.4(0.9)$ & $1-5$ \\
\hline Contact with neighbours & & $3.7(0.9)$ & $1-5$ \\
\hline Social safety & & $3.4(0.9)$ & $1-5$ \\
\hline Shopping facilities & & $3.6(1.0)$ & $1-5$ \\
\hline Green spaces & & $3.6(1.0)$ & $1-5$ \\
\hline
\end{tabular}

Table 1. (Continued)

\begin{tabular}{|c|c|c|c|}
\hline & $N$ (percentage) & Mean (S.D.) & Minimum-Maximum \\
\hline \multicolumn{4}{|l|}{ Social networks } \\
\hline Most friends live in neighbourhood ( $\mathrm{ref} .=$ no) & $88(8.0)$ & & \\
\hline Family lives in neighbourhood (ref. = no) & $220(20.1)$ & & \\
\hline Contact with neighbours) (ref. = no) & $867(79.2)$ & & \\
\hline \multicolumn{4}{|l|}{ Neighbourhood-level variables } \\
\hline Percentage ethnic minorities ${ }^{d}$ & & $21.3(16.0)$ & $5.4-73.4$ \\
\hline Distance to city centre (kilometres) & & $2.1(1.1)$ & $0-4.5$ \\
\hline Crime rates (per 1000 residents and jobs) & & $104.1(34.6)$ & $13.7-174.9$ \\
\hline $\begin{array}{l}\text { Average yearly income of households } \\
(\mathrm{x} 1000 €)\end{array}$ & & $30.3(6.6)$ & $23.3-45.0$ \\
\hline Number of government institutions & & $8.7(4.3)$ & $4.3-17.6$ \\
\hline $\begin{array}{l}\text { Density (number of households } \\
\text { per square } \mathrm{km} \text { ) }\end{array}$ & & $8,640(4,144)$ & $13,03-18,262$ \\
\hline \multicolumn{4}{|c|}{$\begin{array}{l}\text { "Ethnic minorities are defined as people who categorise themselves as members of an ethnic group } \\
\text { from Africa, Asia, Latin America, Turkey, Surinam or the Dutch Antilles. } \\
\text { 'Defined as the respondent's highest completed level of education (low = primary education + } \\
\text { lower vocational training; middle = secondary education/high school, middle vocational training; } \\
\text { high = higher vocational training + university). }\end{array}$} \\
\hline
\end{tabular}




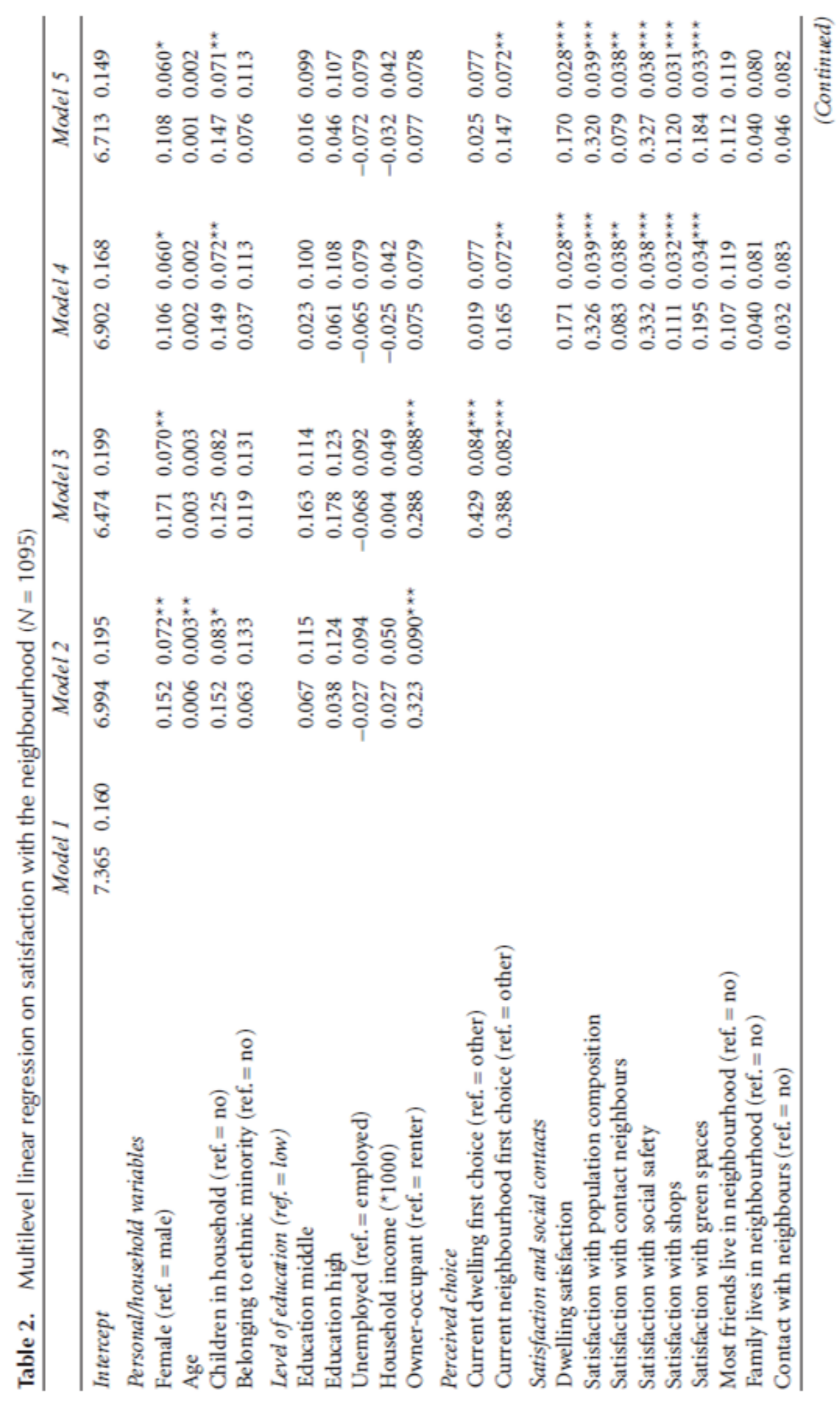




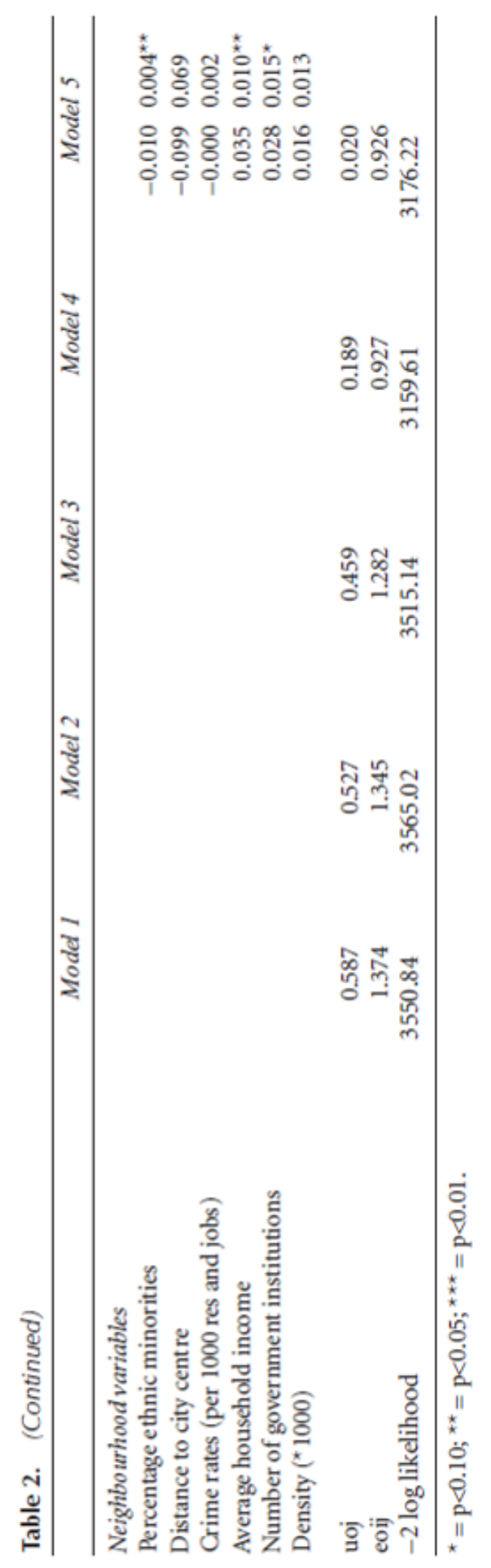




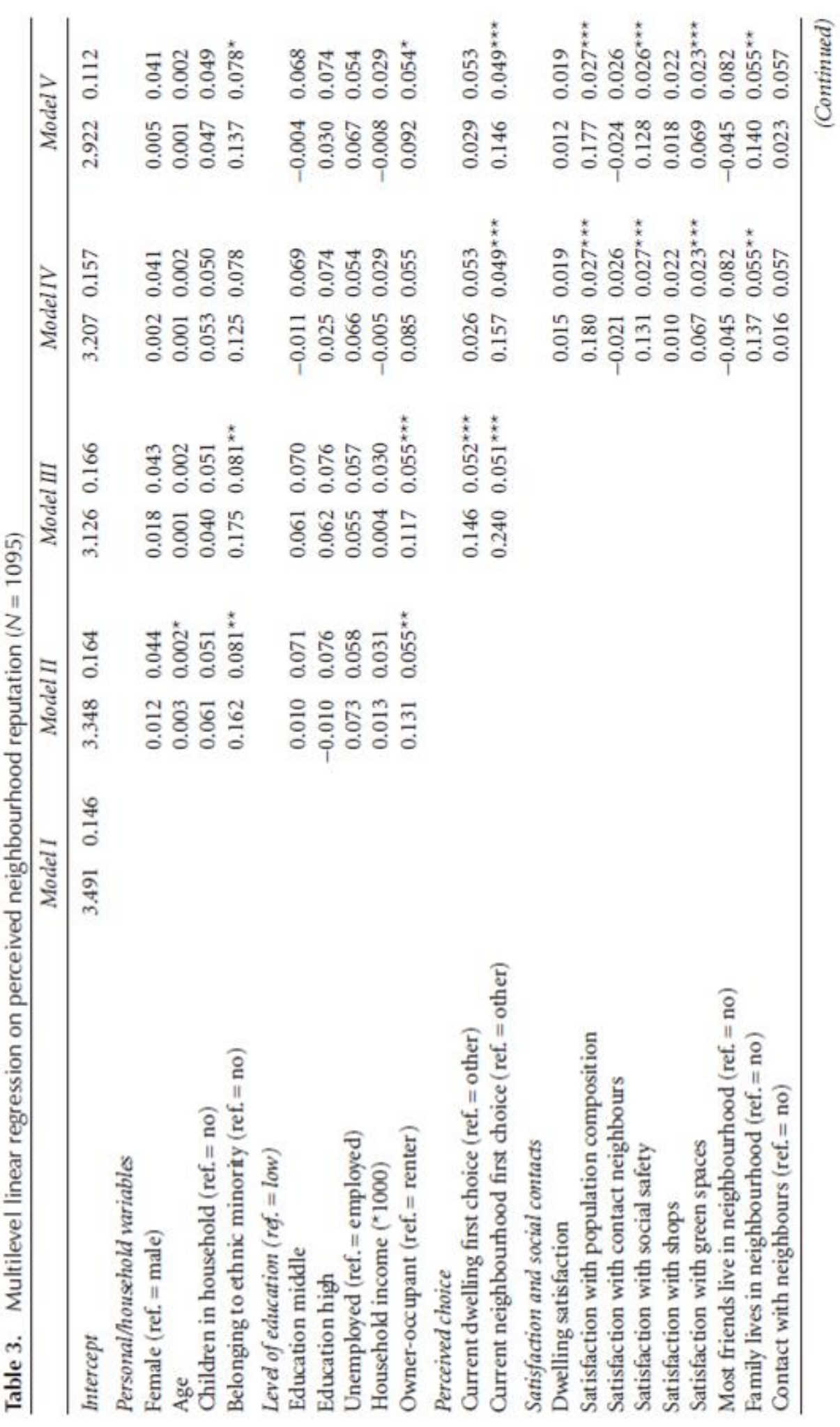




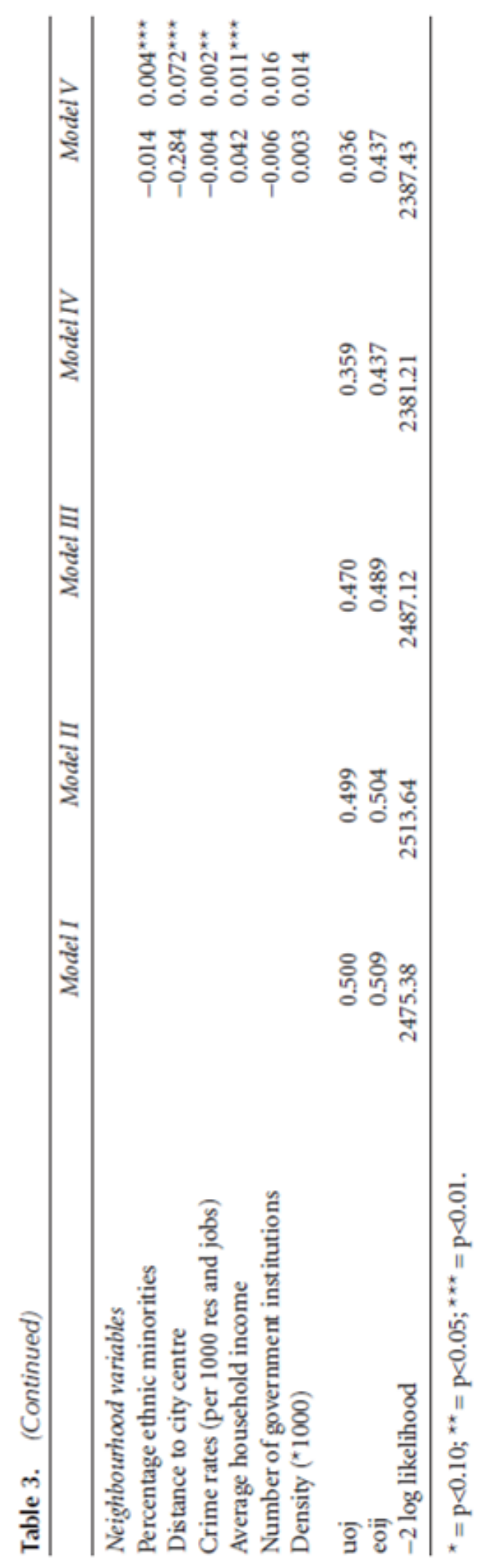


Table 4. Explained variance on level 1 and level 2 for the different models compared with the intercept-only model

\begin{tabular}{|c|c|c|c|c|c|}
\hline & & \multicolumn{2}{|c|}{$\begin{array}{l}\text { Neighbourhood } \\
\text { satisfaction }\end{array}$} & \multicolumn{2}{|c|}{$\begin{array}{c}\text { Perceived } \\
\text { neighbourhood } \\
\text { reputation }\end{array}$} \\
\hline & & Level 1 & Level 2 & Level 1 & Level 2 \\
\hline Model 2/II & Personal/household characteristics & 4.6 & 9.9 & 0.5 & 0.1 \\
\hline Model 3/III & Perceived choice & 11.2 & 21.0 & 4.9 & 6.0 \\
\hline Model 4/IV & Satisfaction and social contacts & 43.1 & 66.1 & 21.1 & 27.8 \\
\hline Model 5/V & Neighbourhood variables & - & 93.3 & - & 91.1 \\
\hline
\end{tabular}

Note: Model 1 is absent, since this model contains no explanatory variables. 